\title{
Comparison of clinical outcomes and left ventricular remodeling after ST-elevation myocardial infarction between patients with and without diabetes mellitus
}

\author{
Naoyuki Akashi ${ }^{1} \cdot$ Takunori Tsukui $^{1} \cdot$ Kei Yamamoto $^{1} \cdot$ Masaru Seguchi $^{1} \cdot$ Yousuke Taniguchi $^{1} \cdot$ Kenichi Sakakura $^{1}$. \\ Hiroshi Wada ${ }^{1} \cdot$ Shin-ichi Momomura ${ }^{1} \cdot$ Hideo Fujita $^{1}$ (D)
}

Received: 26 October 2020 / Accepted: 5 March 2021 / Published online: 14 March 2021

(c) The Author(s) 2021

\begin{abstract}
Left ventricular remodeling (LVR) after ST-elevation myocardial infarction (STEMI) is generally thought to be an adaptive but compromising phenomenon particularly in patients with diabetes mellitus (DM). However, whether the extent of LVR is associated with poor prognostic outcome with or without DM after STEMI in the modern era of reperfusion therapy has not been elucidated. This was a single-center retrospective observational study. Altogether, 243 patients who were diagnosed as having STEMI between January 2016 and March 2019, and examined with echocardiography at baseline (at the time of index admission) and mid-term (from 6 to 11 months after index admission) follow-up were included and divided into the DM $(n=98)$ and non-DM groups $(n=145)$. The primary outcome was major adverse cardiovascular events (MACEs) defined as the composite of all-cause death, heart failure (HF) hospitalization, and non-fatal myocardial infarction. The median follow-up duration was 621 days (interquartile range: 304-963 days). The DM group was significantly increased the rate of MACEs $(P=0.020)$ and HF hospitalization $(P=0.037)$ compared with the non-DM group, despite of less LVR. Multivariate Cox regression analyses revealed that the patients with DM after STEMI were significantly associated with MACEs (Hazard ratio [HR] 2.79, 95\% confidence interval [CI] 1.20-6.47, P=0.017) and HF hospitalization (HR 3.62, 95\% CI 1.19-11.02, $P=0.023)$ after controlling known clinical risk factors. LVR were also significantly associated with MACEs (HR 2.44, 95\% CI 1.03-5.78, $P=0.044$ ) and HF hospitalization (HR 3.76, 95\% CI 1.15-12.32, $P=0.029$ ). The patients with both DM and LVR had worse clinical outcomes including MACEs and HF hospitalization, suggesting that it is particularly critical to minimize LVR after STEMI in patients with DM.
\end{abstract}

Keywords ST-elevation myocardial infarction · Diabetes mellitus $\cdot$ Left ventricular remodeling $\cdot$ Heart failure hospitalization

\section{Introduction}

Among patients with acute myocardial infarction (AMI), left ventricular remodeling (LVR) is thought to occur as an adaptive phenomenon that later results in structural and functional changes such as left ventricular dilatation and reduction of ejection fraction (LVEF) in response to myocardial injury [1-3]. According to the historical definition

Hideo Fujita

hideofujita@jichi.ac.jp

1 Division of Cardiovascular Medicine, Saitama Medical Center, Jichi Medical University, 1-847 Amanuma, Omiya-ku, Saitama 330-8503, Japan of $>15 \%$ increase in left ventricular end-systolic volume (LVESV), LVR is observed in as many as 30\% of anterior myocardial infarction (MI) cases and approximately $17 \%$ of non-anterior MI cases even with timely primary coronary intervention (PCI) and the use of cardiovascular-protective drugs such as angiotensin-converting enzyme inhibitors or angiotensin II receptor blockers, beta blockers, mineral corticoid receptor antagonists, and statins [4]. Diabetes alone is known to cause $\operatorname{LVR}[5,6]$, and in another concept of diabetes mellitus-related cardiomyopathy (DMCMP), LVR has no other cause besides DM [7].

The extent of LVR is generally believed to be associated with worse long-term clinical outcome along with progression of heart failure (HF). However, whether concomitant diabetes mellitus (DM) is associated with a greater extent 
of LVR that leads to worse clinical outcome in patients with ST-elevation myocardial infarction (STEMI) is still not precisely understood. The purpose of the present study was to elucidate the association between LVR and DM in patients with STEMI who underwent a successful modern acute reperfusion therapy mainly with primary PCI followed by optimal medical therapy (OMT).

\section{Materials and methods}

\section{Study design and population}

A single-center retrospective observational study was conducted. We identified patients with AMI from hospital records in our medical center from January 2016 to March 2019. We included patients with STEMI who underwent an echocardiographic examination at the time of index admission (baseline) and mid-term (from 6 to 11 months) followup. The patients were divided into the DM group (patients with diabetes mellitus on admission) and non-DM group (patients without diabetes mellitus on admission).

\section{Data collection, endpoints and definitions}

Echocardiography was performed by experienced ultrasonographers. Clinical characteristics and outcomes were compared between the DM and non-DM groups. The primary outcomes included major cardiovascular events (MACEs) defined as the composite of all-cause death, HF hospitalization, and non-fatal MI. The secondary outcomes included differences in LVEF, left ventricular mass index (LVMI), left atrial volume index (LAVI), relative wall thickness (RWT), left ventricular end-diastolic volume index (LVEDVI), left ventricular end-systolic volume index (LVESVI), and brain natriuretic peptide (BNP) levels between the index admission and mid-term follow-up. This study was approved by the institutional review board, and written informed consent was waived because of the retrospective study design.

The diagnosis of AMI requires meeting the following criteria: symptoms consistent with AMI; elevated cardiac markers, including cardiac troponin $\mathrm{T}$, troponin I, and/or creatinine phosphokinase (CK; at least twofold increase from the normal upper limit); and ST-segment elevation or depression on electrocardiography compatible with AMI [8-10]. Diagnostic ST-segment elevation was defined as a new ST-segment elevation at the $\mathrm{J}$ point in at least 2 contiguous leads of $2 \mathrm{~mm}(0.2 \mathrm{mV})$, and others were defined as not an ST-segment elevation [11]. Hypertension was defined as a systolic blood pressure (SBP) of $\geq 140 \mathrm{mmHg}$, diastolic blood pressure (DBP) of $\geq 90 \mathrm{mmHg}$, or a medical treatment for hypertension before admission [12]. Dyslipidemia was defined as a total cholesterol level of $\geq 220 \mathrm{mg} / \mathrm{dl}$ or a low-density lipoprotein (LDL) cholesterol level of $\geq 140 \mathrm{mg} / \mathrm{dl}$ or medical treatment for dyslipidemia [13]. DM was defined as a hemoglobin A1C level of $\geq 6.5 \%$ (as the national glycohemoglobin standardization program value), medical treatment for DM, or a history of DM [13]. Stress hyperglycemia, or a predictor of survival and increased risk of adverse events in patients both with and without DM, was defined as admission blood plasma glucose $>140 \mathrm{mg} / \mathrm{dl}$ both with and without a history of DM [14]. Shock was defined as a SBP of $<90 \mathrm{mmHg}$, use of vasopressors to maintain blood pressure, or an attempt of cardiopulmonary resuscitation $[15,16]$. We calculated the estimated glomerular filtration rate (eGFR) from the serum creatinine level at admission, age, weight, and sex, using the following formula: $\mathrm{eGFR}=194 \times \mathrm{Cr}^{1.094} \times \mathrm{age}^{0.287}$ (male), $\mathrm{eGFR}=194 \times \mathrm{Cr}^{1.094} \times$ age $^{0.287} \times 0.739$ (female) [17]. Dual antiplatelet therapy was defined as a combination of antiplatelet medications such as aspirin, clopidogrel, prasugrel, and ticlopidine. We calculated LVMI from interventricular septum thickness (IVST), left ventricular internal dimension in diastole (LVDd), and posterior left ventricular wall thickness (PWT) using the formula recommended by the American Society of Echocardiography as follows: LVMI $=\left\{0.8 \times 1.04 \times\left[(\text { IVST }+ \text { LVDd }+ \text { PWT })^{3}-\right.\right.$ LVDd $\left.^{3}\right]$ $+0.6\}$ /body surface area [18]. RWT was calculated as follows: RWT $=2 \times$ PWT/LVDd [18]. LVEF, LVEDVI, LVESVI, and LAVI were calculated using the modified Simpson's method from two-dimensional, apical, twochamber, and four-chamber views [18]. Remodelers were defined as the patients with LVR, which is an increase in left ventricular end-diastolic volume (LVEDV) between baseline and mid-term follow-up as a continuous variable [19]. Primary PCI was performed within $24 \mathrm{~h}$ of onset using standard techniques via the radial, femoral, or brachial artery. First, we advanced a conventional guidewire across the lesion and used a small balloon or thrombus aspiration catheter. The choice of devices was left to the discretion of each interventional cardiologist. The activated coagulation time was maintained $>250$ s during PCI.

\section{Statistical analysis}

Data are shown as percentage for categorical variables or mean \pm SD for continuous variables. Categorical variables are presented as numbers (percentage) and compared using the chi-square or Fisher's exact test. The Shapiro-Wilk test was performed to determine if the continuous variables were normally distributed. Normally distributed continuous variables were compared between the groups using an unpaired Student $t$ test. Otherwise, continuous variables were compared using the Mann-Whitney $U$ test. Event-free survival 
curves for MACEs were constructed with the Kaplan-Meier method, and the statistical differences between the curves were assessed using the log-rank test. Multivariate Cox regression analysis was performed to find the determinant of MACEs or HF hospitalization. Selected variables including age [20], sex [21], LVR [22] and parameters of glucose metabolism (model 1: DM [23], model 2: stress hyperglycemia [14]) were adopted as independent variables. The hazard ratio (HR) and the $95 \%$ confidence interval (CI) were calculated. All statistical tests were two-sided, and a $P$ value of $<0.05$ was considered statistically significant. We analyzed all data using SPSS ver. 25 for Windows (SPSS, Inc., Chicago, Illinois).

\section{Results}

Altogether, 937 patients with AMI were admitted to our medical center from January 2016 to March 2019. We excluded patients with non-STEMI $(n=432)$, patients with STEMI who did not undergo echocardiography at index admission and/or mid-term follow-up $(n=255)$, and patients who did not exist LVEDV findings at index admission and/ or mid-term follow-up $(n=7)$. The final study population included 243 patients, who were divided into the DM $(n=98)$ and non-DM groups $(n=145)$. The study flowchart is shown in Fig. 1.

The comparison of patient characteristics between the 2 groups is shown in Table 1. The proportion of patients with a history of previous PCI was significantly higher in the DM group (13.3\%) than in the non-DM group (4.8\%; $P=0.019)$. The peak CK level was significantly lower in the DM group $(1660.5 \pm 1491.3 \mathrm{IU} / \mathrm{L})$ than in the non-DM group $(2731.6 \pm 2666.4 \mathrm{IU} / \mathrm{L} ; P=0.002)$. Table 2 shows the angiographic characteristics between the 2 groups. Although the difference was not significant, the patients in the DM group tended to have more diseased vessels than those in the non-DM group $(P=0.081)$.

Table 3 shows a comparison of the echocardiographic findings and BNP levels at baseline and mid-term follow-up between the 2 groups. The temporal changes in LVEF from baseline to mid-term follow-up were significantly increased in the DM group $(4.4 \% \pm 9.9 \%)$ compared with the non-DM group $(1.7 \% \pm 9.6 \% ; P=0.028)$. The temporal changes in
Fig. 1 Study flow chart. $L V E D V$ left ventricular end-diastolic volume, $D M$ diabetes mellitus

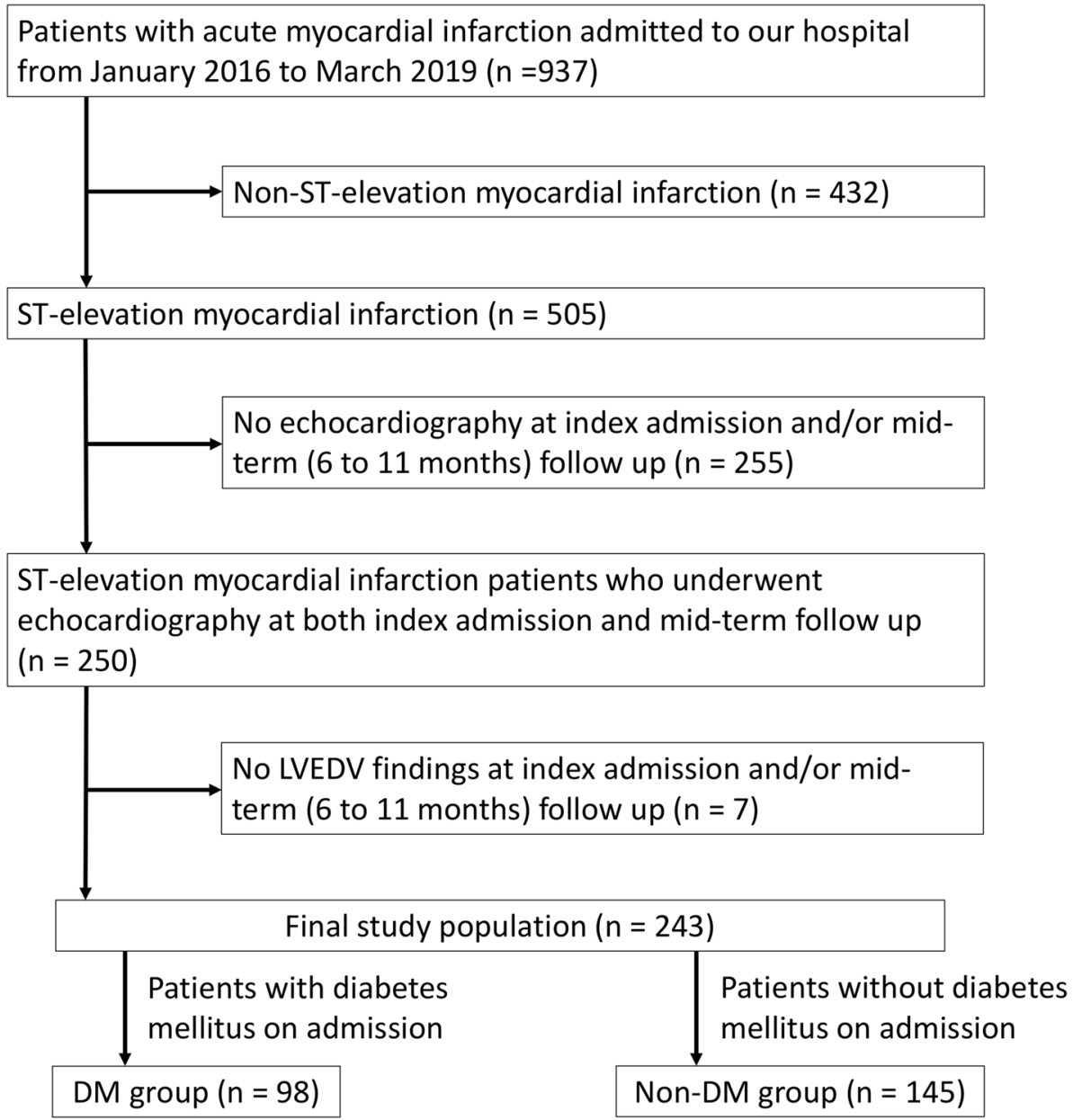


Table 1 Patient characteristics between the DM and the non-DM groups

\begin{tabular}{|c|c|c|c|c|}
\hline & All $(n=243)$ & $\begin{array}{l}\text { DM group } \\
(n=98)\end{array}$ & $\begin{array}{l}\text { non-DM group } \\
(\mathrm{n}=145)\end{array}$ & $P$ value \\
\hline Age, year $(n, \%)$ & $67.0 \pm 13.1(243 / 243,100)$ & $66.7 \pm 12.0$ & $67.2 \pm 13.9$ & 0.74 \\
\hline Female sex, $n(\%)$ & $47 / 243(19.3)$ & $14 / 98(14.3)$ & $33 / 145(22.8)$ & 0.10 \\
\hline Height, $\mathrm{cm}(n, \%)$ & $163.6 \pm 9.2(243 / 243,100)$ & $164.0 \pm 9.0$ & $163.3 \pm 9.3$ & 0.64 \\
\hline Weight, $\operatorname{kg}(n, \%)$ & $65.1 \pm 12.3(243 / 243,100)$ & $67.0 \pm 12.8$ & $63.9 \pm 11.9$ & 0.058 \\
\hline Body mass index, $\mathrm{kg} / \mathrm{m} 2(n, \%)$ & $24.2 \pm 3.3(243 / 243,100)$ & $24.8 \pm 3.5$ & $23.8 \pm 3.1$ & 0.019 \\
\hline Hypertension, $n(\%)$ & $173 / 243(71.2)$ & $75 / 98(76.5)$ & 98/145 (67.6) & 0.13 \\
\hline Dyslipidemia, $n(\%)$ & $129 / 243(53.1)$ & $54 / 98(55.1)$ & $75 / 145(51.7)$ & 0.61 \\
\hline Diabetes mellitus, $n(\%)$ & $98 / 243(40.3)$ & & & \\
\hline Stress hyperglycemia, $n(\%)$ & $143 / 243(58.8)$ & $85 / 98(86.7)$ & $58 / 145(40.0)$ & $<0.001$ \\
\hline Current smoker, $n(\%)$ & $89 / 243(36.6)$ & $36 / 98(36.7)$ & $53 / 145(36.6)$ & 0.98 \\
\hline Past smoker, $n(\%)$ & $88 / 243(36.2)$ & $37 / 98(37.8)$ & $51 / 145(35.2)$ & 0.68 \\
\hline History of previous CABG, n (\%) & $1 / 243(0.4)$ & $0 / 98(0)$ & $1 / 145(0.7)$ & 1.00 \\
\hline History of previous PCI, $n(\%)$ & $20 / 243(8.2)$ & 13/98 (13.3) & $7 / 145(4.8)$ & 0.019 \\
\hline History of previous MI, $n(\%)$ & $15 / 243(6.2)$ & $9 / 98(9.2)$ & $6 / 145(4.1)$ & 0.11 \\
\hline History of previous HF, $n(\%)$ & $1 / 243(0.4)$ & $1 / 98(1.0)$ & $0 / 145(0)$ & 0.40 \\
\hline Killip classification & & & & 0.89 \\
\hline 1 or $2, n(\%)$ & $219 / 243(90.1)$ & $88 / 98(89.8)$ & $131 / 145(90.3)$ & \\
\hline 3 or $4, n(\%)$ & $24 / 243(9.9)$ & $10 / 98(10.2)$ & $14 / 145(9.7)$ & \\
\hline Systolic blood pressure on admission, $\mathrm{mm} \mathrm{Hg}(n, \%)$ & $137.1 \pm 29.2(240 / 243,98.8)$ & $142.0 \pm 30.0$ & $133.9 \pm 28.3$ & 0.041 \\
\hline Diastolic blood pressure on admission, $\mathrm{mm} \mathrm{Hg}(n, \%)$ & $82.0 \pm 18.4(240 / 243,98.8)$ & $80.5 \pm 18.2$ & $83.0 \pm 18.6$ & 0.53 \\
\hline Shock on admission, $n(\%)$ & $20 / 243(8.2)$ & $8 / 98(8.2)$ & $12 / 145(8.3)$ & 0.98 \\
\hline Cardiopulmonary arrest at out of hospital or admission, $n(\%)$ & $8 / 243(3.3)$ & $2 / 98(2.0)$ & $6 / 145(4.1)$ & 0.48 \\
\hline Door to balloon time, $\min (\mathrm{n}, \%)$ & $75.0 \pm 37.3(213 / 243,87.7)$ & $81.9 \pm 44.4$ & $70.7 \pm 31.4$ & 0.12 \\
\hline \multicolumn{5}{|l|}{ Laboratory data } \\
\hline Hemoglobin A1C, \% ( $n, \%)$ & $6.6 \pm 1.5(240 / 243,98.8)$ & $7.9 \pm 1.7$ & $5.8 \pm 0.32$ & $<0.001$ \\
\hline Admission blood plasma glucose, $\mathrm{mg} / \mathrm{dl}(n, \%)$ & $173.6 \pm 79.3(240 / 243,98.8)$ & $222.2 \pm 92.3$ & $141.8 \pm 48.1$ & $<0.001$ \\
\hline Total cholesterol, $\mathrm{mg} / \mathrm{dl}(n, \%)$ & $189.8 \pm 41.5(238 / 243,97.9)$ & $184.6 \pm 42.4$ & $193.2 \pm 40.7$ & 0.065 \\
\hline LDL cholesterol, $\mathrm{mg} / \mathrm{dl}(n, \%)$ & $114.0 \pm 37.4(241 / 243,99.2)$ & $106.2 \pm 36.5$ & $119.3 \pm 37.2$ & 0.004 \\
\hline HDL cholesterol, $\mathrm{mg} / \mathrm{dl}(n, \%)$ & $45.4 \pm 11.3(240 / 243,98.8)$ & $44.5 \pm 12.4$ & $46.0 \pm 10.5$ & 0.15 \\
\hline Triglyceride, $\mathrm{mg} / \mathrm{dl}(n, \%)$ & $126.5 \pm 82.8(243 / 243,100)$ & $138.4 \pm 97.8$ & $118.5 \pm 70.1$ & 0.33 \\
\hline Creatinine, $\mathrm{mg} / \mathrm{dl}(n, \%)$ & $1.1 \pm 1.4(243 / 243,100)$ & $1.5 \pm 2.0$ & $0.85 \pm 0.33$ & 0.16 \\
\hline eGFR, $\mathrm{ml} / \mathrm{min} / 1.73 \mathrm{~m}^{2}(n, \%)$ & $70.4 \pm 27.8(243 / 243,100)$ & $66.4 \pm 32.1$ & $73.1 \pm 24.3$ & 0.082 \\
\hline C-reactive protein, $\mathrm{mg} / \mathrm{dl}(n, \%)$ & $1.5 \pm 3.5(243 / 243,100)$ & $1.9 \pm 3.7$ & $1.3 \pm 3.4$ & 0.031 \\
\hline Uric acid, $\mathrm{mg} / \mathrm{dl}(n, \%)$ & $5.7 \pm 1.4(242 / 243,99.6)$ & $5.4 \pm 1.5$ & $5.8 \pm 1.4$ & 0.012 \\
\hline $\mathrm{BNP}, \mathrm{pg} / \mathrm{ml}(n, \%)$ & $239.3 \pm 432.8(236 / 243,97.1)$ & $319.6 \pm 486.5$ & $186.1 \pm 385.8$ & 0.005 \\
\hline Peak CK, IU/L $(n, \%)$ & $2299.6 \pm 2323.6(243 / 243,100)$ & $1660.5 \pm 1491.3$ & $2731.6 \pm 2666.4$ & 0.002 \\
\hline Peak CK-MB, IU/L $(n, \%)$ & $214.7 \pm 216.9(243 / 243,100)$ & $150.1 \pm 153.5$ & $258.3 \pm 241.7$ & $<0.001$ \\
\hline \multicolumn{5}{|l|}{ Medication on discharge } \\
\hline \multicolumn{5}{|l|}{ Antiplatelet agents } \\
\hline Dual antiplatelet therapy, $n(\%)$ & $229 / 243(94.2)$ & 94/98 (95.9) & $135 / 145(93.1)$ & 0.36 \\
\hline \multicolumn{5}{|l|}{ Antihypertensive medications } \\
\hline ACE-Is, $n(\%)$ & $210 / 243(86.4)$ & 80/98 (81.6) & $130 / 145(89.7)$ & 0.073 \\
\hline ARBs, $n(\%)$ & $28 / 243(11.5)$ & $16 / 98(16.3)$ & $12 / 145(8.3)$ & 0.054 \\
\hline ACE-Is or ARBs, $n(\%)$ & $235 / 243(96.7)$ & 94/98 (95.9) & $141 / 145(97.2)$ & 0.57 \\
\hline$\beta$-blockers, $n(\%)$ & $236 / 243(97.1)$ & 95/98 (96.9) & $141 / 145(97.2)$ & 1.00 \\
\hline Mineralocorticoid receptor antagonists, $n(\%)$ & $38 / 243(15.6)$ & $15 / 98(15.3)$ & 23/145 (15.9) & 0.91 \\
\hline Loop diuretics, $n(\%)$ & $52 / 243(21.4)$ & $22 / 98(22.4)$ & $30 / 145(20.7)$ & 0.74 \\
\hline Thiazide, $n(\%)$ & $2 / 243(0.8)$ & $2 / 98(2.0)$ & $0 / 145(0)$ & 0.16 \\
\hline Tolvaptan, $n(\%)$ & $6 / 243(2.5)$ & $4 / 98(4.1)$ & $2 / 145(1.4)$ & 0.22 \\
\hline
\end{tabular}


Table 1 (continued)

\begin{tabular}{|c|c|c|c|c|}
\hline & All $(n=243)$ & $\begin{array}{l}\text { DM group } \\
(n=98)\end{array}$ & $\begin{array}{l}\text { non-DM group } \\
(\mathrm{n}=145)\end{array}$ & $P$ value \\
\hline Nicorandil, $n(\%)$ & $1 / 243(0.4)$ & $0 / 98(0)$ & $1 / 145(0.7)$ & 1.0 \\
\hline Calcium channel blockers, $n(\%)$ & $24 / 243(9.9)$ & 13/98 (13.3) & $11 / 145(7.6)$ & 0.15 \\
\hline Statin, $n(\%)$ & $239 / 243(98.4)$ & 96/98 (98.0) & $143 / 145(98.6)$ & 1.00 \\
\hline \multicolumn{5}{|l|}{ Antidiabetic medications } \\
\hline SGLT2 inhibitors, $n(\%)$ & $23 / 243(9.5)$ & 23/98 (23.5) & & \\
\hline DPP-4 inhibitors, $n(\%)$ & $66 / 243(27.2)$ & $66 / 98(67.3)$ & & \\
\hline GLP-1 receptor agonists, $n(\%)$ & $2 / 243(0.8)$ & $2 / 98(2.0)$ & & \\
\hline Metformin, $n(\%)$ & $17 / 243(7.0)$ & $17 / 98(17.3)$ & & \\
\hline Sulfonylurea, $n(\%)$ & $13 / 243(5.3)$ & 13/98 (13.3) & & \\
\hline Thiazolidine, $n(\%)$ & $2 / 243(0.8)$ & $2 / 98(2.0)$ & & \\
\hline Glinide, $n(\%)$ & $4 / 243(1.6)$ & $4 / 98(4.1)$ & & \\
\hline$\alpha$-glucosidase inhibitors, $n(\%)$ & $5 / 243(2.1)$ & $5 / 98(5.1)$ & & \\
\hline Insulin, $n(\%)$ & $16 / 243(6.6)$ & $16 / 98(16.3)$ & & \\
\hline No medications, $n(\%)$ & $16 / 243(6.6)$ & $16 / 98(16.3)$ & & \\
\hline
\end{tabular}

$C A B G$ coronary artery bypass grafting, $P C I$ percutaneous coronary intervention, $M I$ myocardial infarction, $H F$ heart failure, $H D L$ high-density lipoprotein, $L D L$ low-density lipoprotein, $e G F R$ estimated glomerular filtration rate, $B N P$ brain natriuretic peptide, $C K$ creatine kinase, $A C E-I S$ angiotensin converting enzyme-inhibitors, $A R B s$ angiotensin receptor blockers, $S G L T$ sodium glucose transporter, $D P P$ dipeptidyl peptidase, GLP glucagon like peptide

Table 2 Angiographic characteristics between the DM and the non-DM groups

\begin{tabular}{lllll}
\hline & All $(n=243)$ & $\begin{array}{l}\text { DM group } \\
(n=98)\end{array}$ & $\begin{array}{l}\text { non-DM group } \\
(n=145)\end{array}$ & $P$ value \\
\hline $\begin{array}{l}\text { Primary PCI, } n(\%) \\
\text { Culprit of AMI, } n(\%)\end{array}$ & $196 / 243(80.7)$ & $75 / 98(76.5)$ & $121 / 145(83.4)$ & 0.18 \\
$\begin{array}{l}\text { Left main trunk and/or Left ante- } \\
\text { rior descending artery }\end{array}$ & $137 / 243(56.4)$ & $55 / 98(56.1)$ & $82 / 145(56.6)$ & \\
Left circumflex artery & $25 / 243(10.3)$ & $10 / 98(10.2)$ & $15 / 145(10.3)$ & \\
Right coronary artery & $81 / 243(33.3)$ & $33 / 98(33.7)$ & $48 / 145(33.1)$ & \\
Graft, $n(\%)$ & $0 / 243(0)$ & $0 / 98(0)$ & $0 / 145(0)$ & 0.081 \\
Not determined & $0 / 243(0)$ & $0 / 98(0)$ & $0 / 145(0)$ & \\
Number of diseased vessels, $n(\%)$ & & & & \\
Single & $126 / 243(51.9)$ & $43 / 98(43.9)$ & $83 / 145(57.2)$ & \\
Double & $71 / 243(29.2)$ & $31 / 98(31.6)$ & $40 / 145(27.6)$ & \\
Triple & $46 / 243(18.9)$ & $24 / 98(24.5)$ & $22 / 145(15.2)$ & \\
IABP before PCI, $n(\%)$ & $22 / 243(9.1)$ & $11 / 98(11.2)$ & $11 / 145(7.6)$ & 0.33 \\
VA-ECMO before PCI, $n(\%)$ & $2 / 243(0.8)$ & $0 / 98(0)$ & $2 / 145(1.4)$ & 0.52 \\
\hline
\end{tabular}

$P C I$ percutaneous coronary intervention, $A M I$ acute myocardial infarction, $I A B P$ intra-aortic balloon pumping, $V A-E C M O$ venoarterial-extracorporeal membrane oxygenation
LVDd, LVDs, RWT, LVESVI, and BNP levels from baseline to mid-term follow-up were significantly decreased in the DM group compared with the non-DM group. The temporal changes in LVEF, LVEDVI, LVESVI, LAVI, $E / e^{\prime}$, and BNP levels from baseline to mid-term follow-up are shown in Fig. 2. E/e $e^{\prime}$ was significantly greater in the DM group than in the non-DM group at baseline and mid-term follow-up $(17.4 \pm 6.4$ vs. $15.0 \pm 6.0, P=0.001$ and $16.0 \pm 6.6$ vs. $13.8 \pm 5.3, P=0.001$, respectively). The BNP levels at baseline were significantly higher in the DM group than in the non-DM group $(319.6 \pm 486.5$ vs. $186.1 \pm 385.8 \mathrm{pg} / \mathrm{ml}$, $P=0.005)$. The temporal changes in LVEDVI, LAVI and $E / e^{\prime}$ from baseline to mid-term follow-up showed no significant difference between the 2 groups. 


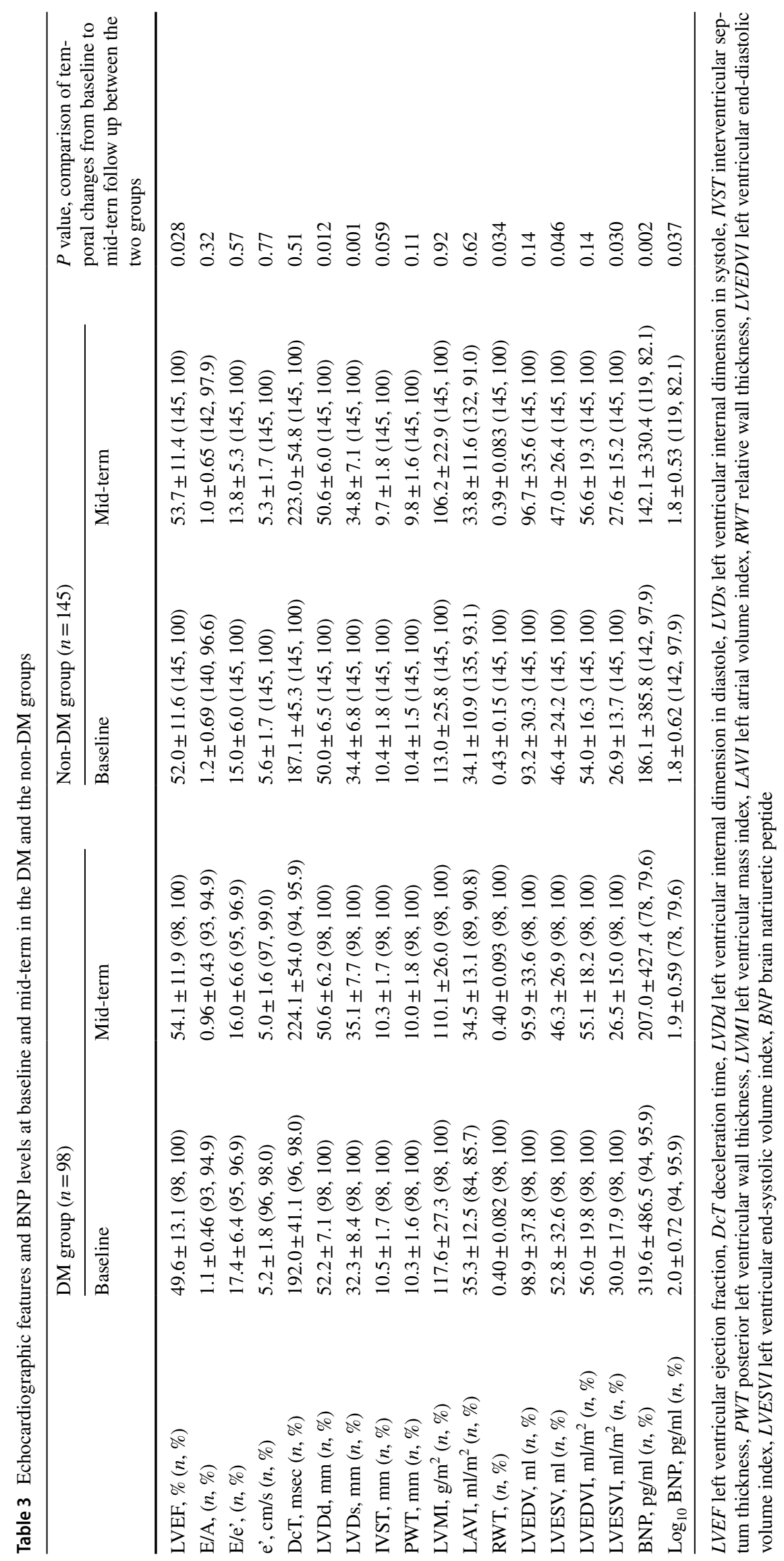




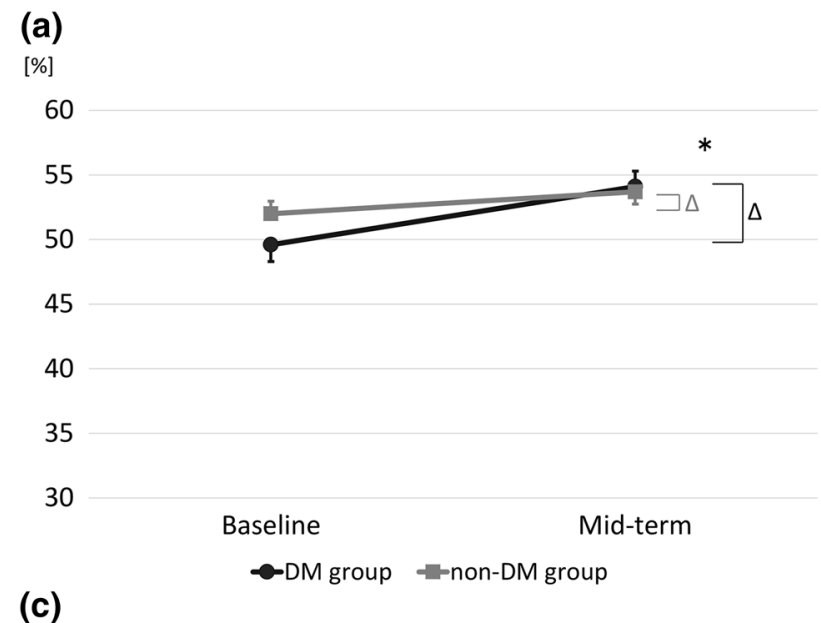
$\left[\mathrm{ml} / \mathrm{m}^{2}\right]$

40

36

32

28

24

20

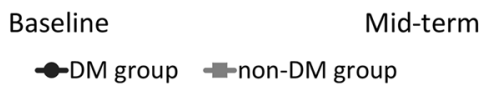

(e)

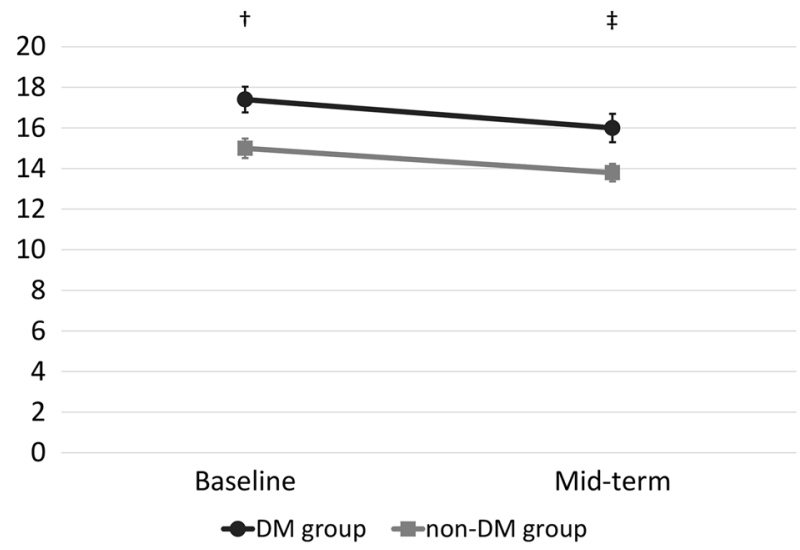

Fig. 2 Comparison of temporal changes in left ventricular ejection fraction (LVEF) (a), left ventricular end-diastolic volume index (LVEDVI) (b), left ventricular end-systolic volume index (LVESVI) (c), left atrial volume index (LAVI) $(\mathbf{d}), E / e^{\prime}(\mathbf{e})$, and brain natriuretic peptide (BNP) levels (f) from baseline to mid-term follow-up in

The Kaplan-Meier curves are shown in Fig. 3. During the study period, the number of MACEs was 24, and the number of HF hospitalizations was 15 . The incidence of MACEs was significantly higher in the DM group than in the non-DM group (log-rank test; $P=0.020$ ). The rate of (b)

$$
\left[\mathrm{ml} / \mathrm{m}^{2}\right]
$$

70

$65 \longrightarrow P=0.14$

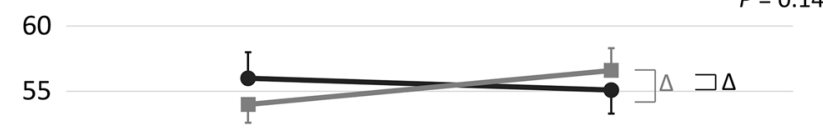

50

45

40

(d)

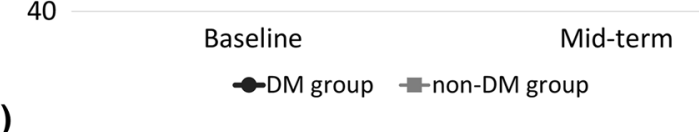

$\left[\mathrm{ml} / \mathrm{m}^{2}\right]$

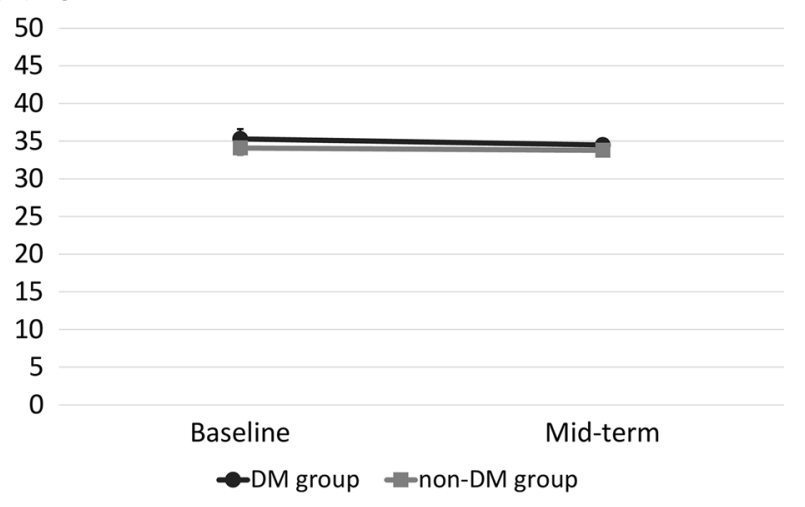

(f)

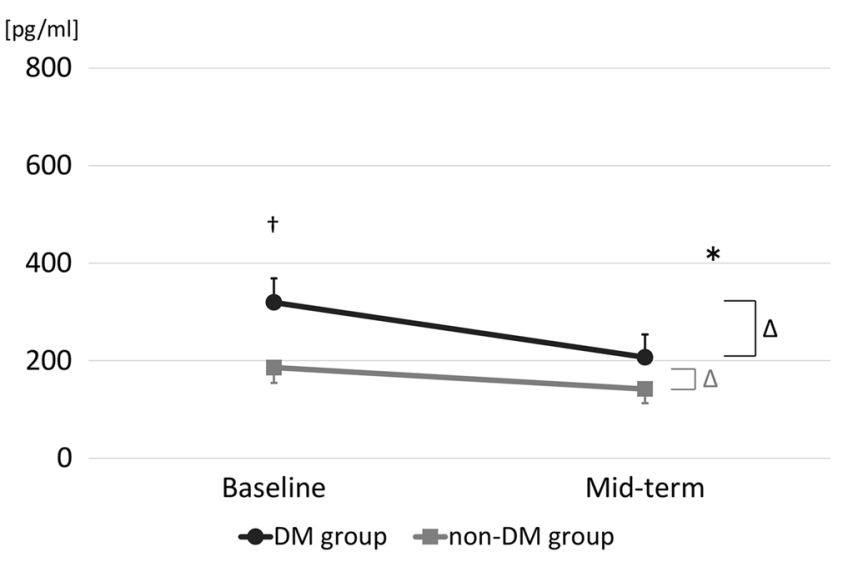

the patients with diabetes (solid circles) and without diabetes (solid squares). $* P<0.05$ changes from baseline to mid-tern follow-up between the 2 groups; ${ }^{\dagger} P<0.05$ between the 2 groups at baseline; ${ }^{\ddagger} P<0.05$ between the 2 groups at mid-term follow-up. Data are mean $\pm \mathrm{SE}$

HF hospitalization was significantly higher in the DM group than in the non-DM group (log-rank test; $P=0.037$ ). No significant differences in all-cause death and non-fatal MI were found between the 2 groups. In multivariate Cox regression analyses, DM was significantly associated with MACEs (HR 

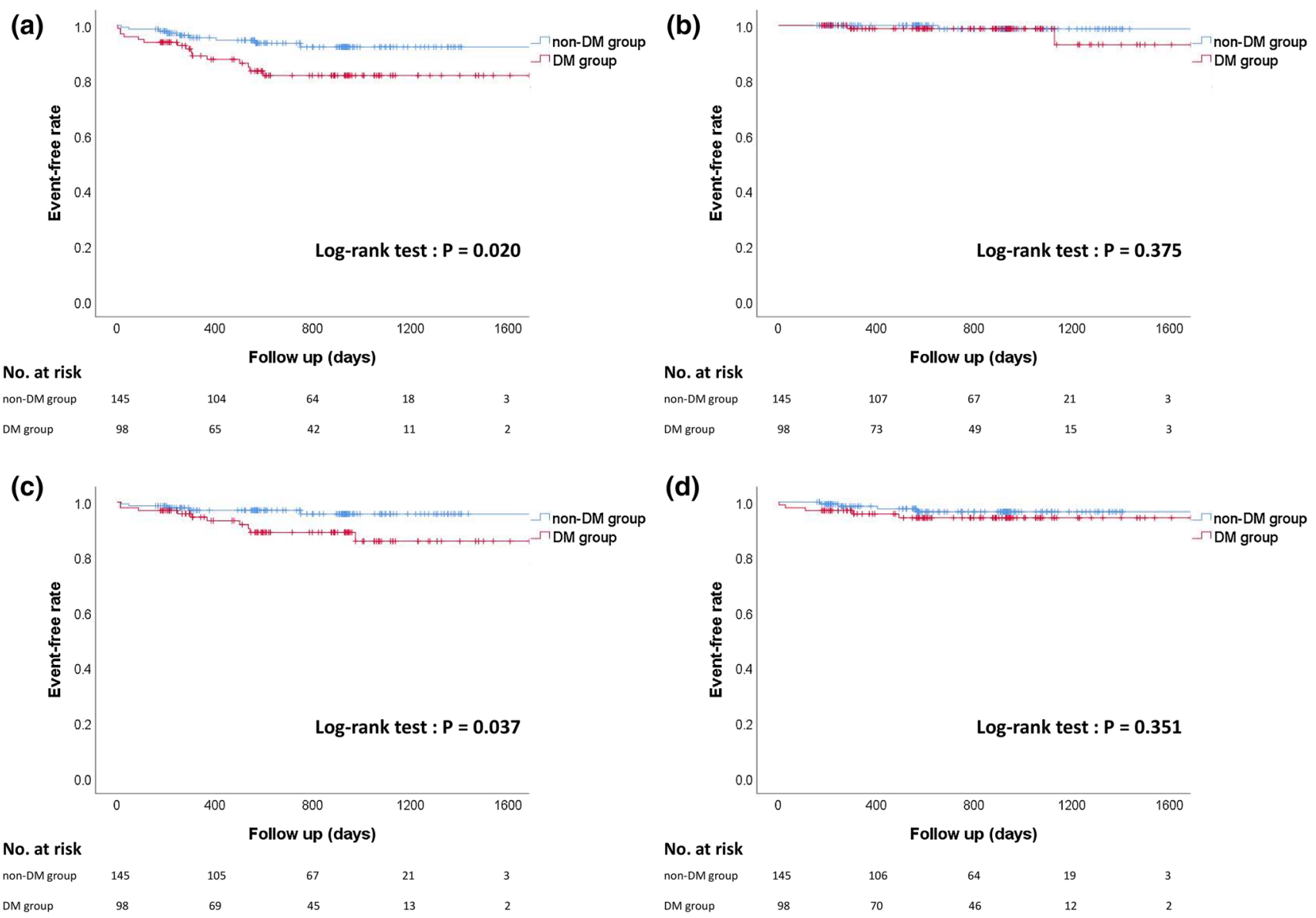

Fig. 3 Kaplan-Meier curves for major adverse cardiac events (MACEs) (a), all-cause death (b), heart failure (HF) hospitalization (c), and nonfatal myocardial infarction (MI) (d) between the DM and non-DM groups. The $P$ values were calculated using a log-rank test

Table 4 Multivariate Cox regression analysis predicting MACEs

\begin{tabular}{llll}
\hline Dependent variable: MACE & & & \\
\hline Independent variables & HR & $95 \%$ CI & $P$ value \\
\hline Model 1 & & & \\
Age (per 1 year) & 1.02 & $0.99-1.06$ & 0.23 \\
Female sex (vs. male sex) & 0.69 & $0.20-2.40$ & 0.55 \\
DM & 2.79 & $1.20-6.47$ & 0.017 \\
LVR & 2.44 & $1.03-5.78$ & 0.044 \\
\hline Dependent variable: MACE & & & \\
\hline Independent variables & HR & $95 \%$ CI & $P$ value \\
\hline Model 2 & & & \\
Age (per 1 year) & 1.02 & $0.99-1.06$ & 0.21 \\
Female sex (vs. male sex) & 0.56 & $0.16-1.94$ & 0.36 \\
Stress hyperglycemia & 1.64 & $0.68-3.95$ & 0.27 \\
LVR & 2.09 & $0.89-4.92$ & 0.09 \\
\hline
\end{tabular}

MACE major adverse cardiac event, $H R$ hazard ratio, $C I$ confidence interval, $D M$ diabetes mellitus, $L V R$ left ventricular remodeling
$2.79,95 \%$ CI 1.20-6.47, $P=0.017)$ and HF hospitalization (HR 3.62, 95\% CI 1.19-11.02, $P=0.023$ ) after controlling age, sex and LVR (Model 1 in Tables 4 and 5). LVR was also significantly associated with MACEs (HR 2.44, 95\% CI 1.03-5.78, $P=0.044$ ) and HF hospitalization (HR 3.76, 95\% CI 1.15-12.32, $P=0.029)$ after controlling age, sex and DM (Model 1 in Tables 4 and 5). However, stress hyperglycemia was not significantly associated with MACE and HF hospitalization after controlling age, sex and LVR (Model 2 in Tables 4 and 5).

\section{Discussion}

The present study included 243 consecutive patients with STEMI who underwent reperfusion therapy and were categorized into the DM group $(n=98)$ and non-DM group $(n=145)$. The structural changes of the patients' hearts were examined with echocardiography both at index admission 
Table 5 Multivariate Cox regression analysis predicting HF hospitalization

\begin{tabular}{llll}
\hline Dependent variable: HF hospitalization & & & \\
\hline Independent variables & HR & $95 \%$ CI & \\
\hline Model 1 & & & \\
Age (per 1 year) & 1.03 & $0.99-1.08$ & $0.35-5.23$ \\
Female sex (vs. male sex) & 1.35 & $1.19-11.02$ & 0.17 \\
DM & 3.62 & $1.15-12.32$ & 0.66 \\
LVR & 3.76 & & 0.023 \\
\hline Dependent variable: HF hospitalization & & $95 \%$ CI & 0.029 \\
\hline Independent variables & HR & & $P$ value \\
\hline Model 2 & & $0.99-1.08$ \\
Age (per 1 year) & 1.03 & $0.27-3.76$ \\
Female sex (vs. male sex) & 1.01 & $0.58-5.74$ & 0.16 \\
Stress hyperglycemia & 1.82 & $0.96-9.75$ & 0.98 \\
LVR & 3.06 & & 0.31 \\
\hline
\end{tabular}

Abbreviations are the same as Table 4

and mid-term follow-up. First, we demonstrated that the DM group had a higher MACEs and HF hospitalization rate than the non-DM group. Second, the structural changes in LV, represented by LVDd, LVDs and LVESVI, were significantly decreased in the DM group compared with the non-DM group. LV functional changes represented by LVEF were significantly increased in the DM group compared with the non-DM group. Third, the degree of temporal decrease in BNP levels from baseline to mid-term follow-up was significantly greater in the DM group than in the non-DM group. Our study suggests that the patients with DM after STEMI have the inverse correlation between MACEs and the LV structural changes. However, we performed multivariate Cox regression analyses predicting MACEs and HF hospitalization, both DM and LVR were significantly associated with MACEs and HF hospitalization. Meanwhile, we performed multivariate Cox regression analyses predicting MACEs and HF hospitalization with the independent variables changed from DM to stress hyperglycemia, stress hyperglycemia was not significantly associated with MACEs and HF hospitalization.

As several studies demonstrated, DM is a strong risk factor of the progression of HF [7, 24-26]. Patients with DM have from 2 to 5 times greater risk of HF than those in the general population [24, 27]. Generally, patients with DM, even those without symptomatic $\mathrm{HF}$, tend to have LV diastolic dysfunction in the presence of increasing LV stiffness and LV mass with normal systolic function [25, 28]. In our study, $E / e^{\prime}$, or the index of diastolic function, was significantly higher in the DM group than in the non-DM group both at baseline and mid-term follow-up, consistent with the results of previous studies; However, LAVI, or an indirect correlate of LV filling pressures over time, was not significantly different between the 2 groups both at baseline and mid-term follow-up. This may be because $E / e$ ' that includes the movement of mitral annular early diastolic velocity $(e$ ') can reflect changes in the myocardial movement more directly than measurement of LAVI [29].

The progression of HF in patients after MI is mainly associated with LVR [1], which is a heterogeneous process affected by various factors, including infarct size, transmural infarction, microvascular obstruction, myocardial hemorrhage, and advanced patient age [30, 31]. One prospective single-center study demonstrated that LVR after successful primary percutaneous transluminal coronary angioplasty (PTCA) occurred despite preservation of regional and global LV functions measured using echocardiography, and the presence of LVR at 6 months after AMI was significantly associated with cardiac death and hospitalization for chronic HF [32]. Meanwhile, in the modern era of primary PCI and OMT, van der Bijl et al. echocardiographically investigated the interaction between LV post-infarct remodeling with $\mathrm{LV}$ systolic function and the long-term prognostic impact of such remodeling [22]. During 94 months follow-up, they showed no significant differences in long-term mortality between LV remodelers and non-remodelers, and that the LV remodelers had a significantly higher HF hospitalization rate than the nonremodelers. These 2 studies both demonstrated that LV post-infarct remodeling after successful PCI was associated with HF hospitalization, not with long-term mortality.

By contrast, the present study demonstrated that LVESVI changes from baseline to mid-term follow-up were significantly decreased in the DM group compared with the 
non-DM group. LVEDVI changes also tended to decrease in the DM group than in the non-DM group. In other words, patients with DM echocardiographically presented reverse remodeling to a larger extent during 6 to 11 months after STEMI than those without DM. Previous studies have demonstrated that infarct size was associated with LVR [30, 33] and anterior MI presented a significantly larger infarct size than non-anterior MI [34]. In the present cohort, the accurate infarct size could not be shown because we did not routinely perform cardiac magnetic resonance imaging (CMR) and single photon emission computed tomography (SPECT) to detect infarct size. Additionally, the rate of infarct-related artery was not significantly different between the 2 groups. The reason why the DM group echocardiographically presented reverse remodeling than the non-DM group is unclear in our study.

Nevertheless, we found that MACEs and HF hospitalization rate were significantly higher in the patients with DM than in those without DM. The echocardiographic substudy in the SAVE trial also reported that the increased incidence of HF after MI in patients with DM was not explained by the increasing trend for LVR in the nondiabetic patients with similar-sized infarcts [35]. The findings that patients with DM after STEMI may develop HF with less LV enlargement than those without DM after STEMI are contrary to the established concepts that LVR progresses to HF in all patients. Furthermore, one multicenter and prospective study demonstrated that DM remains an independent predictor of HF hospitalization in patients with a modern treatment of MI including acute reperfusion therapy followed by optimal medical therapy, although this higher risk is not associated with a decreased LVEF or an increased propensity to LVR but with LV diastolic dysfunction [36]. As mentioned in these 2 studies, this inverse relationship between LVR and HF progression in patients with DM may be associated with increased filling pressure, which is supported by the finding that BNP levels at baseline and mid-term follow-up were higher in the DM group than in the non-DM group. To our knowledge, this is the first study to show that the extent of LVR was less in patients with DM than in those without DM, although BNP levels were higher in the patients with than in those without DM after STEMI. Moreover, a previous study demonstrated that the patients with DM, even with short diabetes duration and good glycemic control, impaired diastolic function [37]. In the present study, the patients with DM after STEMI were significantly increased the rate of MACEs, notably HF hospitalization, despite of less LVR. This suggests that the patients with DM after STEMI may be hospitalized for HF because of increased filling pressure before LVR occurs.

However, according to multivariate Cox regression analyses shown in Tables 4 and 5, the patients with both DM and LVR had worse clinical outcomes including MACEs and HF hospitalization. In brief, if we focused on patients with LVR, those who had DM after STEMI had significantly higher HF hospitalization rate, despite that the patients with DM after STEMI tended to present reverse remodeling. Our data indicate that treatment of patients with DM after STEMI is particularly important for the prevention of LVR, including administration of an angiotensin receptor neprilysin inhibitor $[38,39]$ and sodium glucose cotransporter type 2 inhibitors [40].

\section{Study limitations}

This study has several limitations. First, because this study was a single-center retrospective observational study with a small number of patients, selection bias may exist. We could not conduct propensity score matching to fit the difference in background between the 2 groups, as the sample size was relatively small. Therefore, the difference between the 2 groups may have affected the results. Second, as we performed the echocardiographic analysis on-site, the echocardiographic measurements may have differed between ultrasonographers. Additionally, as the number of LAVI measurements both at baseline and mid-term follow-up was less than other measurements owing to inappropriate image detection, it may not reflect the exact differences in LV filling pressures between the 2 groups. Third, a beta error is possible in the comparisons between the DM and non-DM groups, as the total study population was relatively small $(n=243)$. Fourth, we could not evaluate the long-term outcomes because the followup duration may not be sufficiently long (median, 621 days [interquartile range, 304-963 days]). A larger sample size and longer follow-up might be needed. Fifth, there may have been some differences in the extent of LVR between cases since mid-term echocardiographic follow-up duration is slightly too long to evaluate LVR. Finally, the peak CK level, that was significantly lower in the DM group than in the non-DM group, could not correctly reflect the infarct size, because the patients with delayed arrival included in the present study. We could not evaluate the accurate infarct size, because we did not routinely perform CMR and SPECT after the admission.

\section{Conclusions}

As compared with the patients without DM, those with DM after STEMI had a higher MACEs and HF hospitalization rate; nevertheless, the extent of LVR was less in the patients with than in those without DM. However, the patients with both DM and LVR after STEMI were significantly associated with worse clinical outcomes including MACEs and HF 
hospitalization, which suggests that minimizing LV remodeling after STEMI is particularly critical in patients with DM.

Acknowledgements The authors acknowledge all staff in the catheter laboratory in Saitama Medical Center, Jichi Medical University for their technical support in this study.

\section{Declarations}

Conflict of interest The authors declare that they have no conflict of interest.

Open Access This article is licensed under a Creative Commons Attribution 4.0 International License, which permits use, sharing, adaptation, distribution and reproduction in any medium or format, as long as you give appropriate credit to the original author(s) and the source, provide a link to the Creative Commons licence, and indicate if changes were made. The images or other third party material in this article are included in the article's Creative Commons licence, unless indicated otherwise in a credit line to the material. If material is not included in the article's Creative Commons licence and your intended use is not permitted by statutory regulation or exceeds the permitted use, you will need to obtain permission directly from the copyright holder. To view a copy of this licence, visit http://creativecommons.org/licenses/by/4.0/.

\section{References}

1. Pfeffer MA, Braunwald E (1990) Ventricular remodeling after myocardial infarction. Experim Observ Clin Impl Circul 81:1161-1172

2. Giannuzzi P, Temporelli PL, Bosimini E, Gentile F, Lucci D, Maggioni AP, Tavazzi L, Badano L, Stoian I, Piazza R, Heyman I, Levantesi G, Cervesato E, Geraci E, Nicolosi GL (2001) Heterogeneity of left ventricular remodeling after acute myocardial infarction: results of the Gruppo Italiano per lo Studio della Sopravvivenza nell' Infarto Miocardico-3 Echo Substudy. Am Heart J 141:131-138

3. Ishii H, Amano T, Matsubara T, Murohara T (2008) Pharmacological intervention for prevention of left ventricular remodeling and improving prognosis in myocardial infarction. Circulation 118:2710-2718

4. Masci PG, Ganame J, Francone M, Desmet W, Lorenzoni V, Iacucci I, Barison A, Carbone I, Lombardi M, Agati L, Janssens S, Bogaert J (2011) Relationship between location and size of myocardial infarction and their reciprocal influences on post-infarction left ventricular remodelling. Eur Heart J 32:1640-1648

5. Galderisi M (2006) Diastolic dysfunction and diabetic cardiomyopathy: evaluation by Doppler echocardiography. J Am Coll Cardiol 48:1548-1551

6. Wang Q, Tan K, Xia H, Gao Y (2019) Left ventricular metabolic remodeling and accompanied dysfunction in type 2 diabetic patients: A 3D speckle tracking analysis. Echocardiography 36:486-494

7. Seferovic PM, Paulus WJ (2015) Clinical diabetic cardiomyopathy: a two-faced disease with restrictive and dilated phenotypes. Eur Heart J 36(1718-1727):1727a-1727c

8. Akashi N, Sakakura K, Watanabe Y, Noguchi M, Taniguchi Y, Yamamoto K, Wada H, Momomura SI, Fujita H (2018) The comparison of clinical outcomes in patients with acute myocardial infarction and advanced chronic kidney disease on chronic hemodialysis versus off hemodialysis. Heart Vessels 33:713-721
9. Yamamoto K, Sakakura K, Akashi N, Watanabe Y, Noguchi M, Taniguchi Y, Wada H, Momomura SI, Fujita H (2019) Comparison of Clinical Outcomes between the Ostial Versus Non-Ostial Culprit in Proximal Left Anterior Descending Artery Acute Myocardial Infarction. Int Heart J 60:37-44

10. Ohashi J, Sakakura K, Yamamoto K, Taniguchi Y, Tsukui T, Seguchi M, Nanba-Sato H, Shibata K, Sasaki W, Ikeda T, Wada H, Momomura SI, Fujita H (2019) Determinants of Improvement of Mid-term Ejection Fraction in Patients with Acute Myocardial Infarction. Int Heart J 60:1245-1252

11. Tsukui T, Sakakura K, Taniguchi Y, Yamamoto K, Wada H, Momomura SI, Fujita H (2018) Determinants of short and long door-to-balloon time in current primary percutaneous coronary interventions. Heart Vessels 33:498-506

12. Yamamoto K, Sakakura K, Akashi N, Watanabe Y, Noguchi M, Seguchi M, Taniguchi Y, Ugata Y, Wada H, Momomura SI, Fujita H (2019) Novel Acute Myocardial Infarction Risk Stratification (nARS) System Reduces the Length of Hospitalization for Acute Myocardial Infarction. Circ J 83:1039-1046

13. Noguchi M, Sakakura K, Akashi N, Adachi Y, Watanabe Y, Taniguchi Y, Ibe T, Yamamoto K, Wada H, Momomura SI, Fujita H (2019) The Comparison of clinical outcomes between inferior st-elevation myocardial infarction with right ventricular infarction versus without right ventricular infarction. Int Heart J 60:560-568

14. Deedwania P, Kosiborod M, Barrett E, Ceriello A, Isley W, Mazzone T, Raskin P (2008) Hyperglycemia and acute coronary syndrome: a scientific statement from the American Heart Association Diabetes committee of the council on nutrition, physical activity, and metabolism. Circulation 117:1610-1619

15. Watanabe Y, Sakakura K, Taniguchi Y, Adachi Y, Noguchi M, Akashi N, Wada H, Momomura SI, Fujita H (2016) Determinants of in-hospital death in acute myocardial infarction with triple vessel disease. Int Heart J 57:697-704

16. Hoebers LP, Vis MM, Claessen BE, van der Schaaf RJ, Kikkert WJ, Baan J Jr, de Winter RJ, Piek JJ, Tijssen JG, Dangas GD, Henriques JP (2013) The impact of multivessel disease with and without a co-existing chronic total occlusion on short- and longterm mortality in ST-elevation myocardial infarction patients with and without cardiogenic shock. Eur J Heart Fail 15:425-432

17. Matsuo S, Imai E, Horio M, Yasuda Y, Tomita K, Nitta K, Yamagata K, Tomino Y, Yokoyama H, Hishida A (2009) Revised equations for estimated GFR from serum creatinine in Japan. Am J Kidney Dis 53:982-992

18. Lang RM, Badano LP, Mor-Avi V, Afilalo J, Armstrong A, Ernande L, Flachskampf FA, Foster E, Goldstein SA, Kuznetsova T, Lancellotti P, Muraru D, Picard MH, Rietzschel ER, Rudski L, Spencer KT, Tsang W, Voigt JU (2015) Recommendations for cardiac chamber quantification by echocardiography in adults: an update from the American Society of Echocardiography and the European Association of Cardiovascular Imaging. J Am Soc Echocardiogr 28:1-39.e14

19. Solomon SD, Anavekar NS, Greaves S, Rouleau JL, Hennekens C, Pfeffer MA (2004) Angina pectoris prior to myocardial infarction protects against subsequent left ventricular remodeling. J Am Coll Cardiol 43:1511-1514

20. Wellings J, Kostis JB, Sargsyan D, Cabrera J, Kostis WJ (2018) Risk factors and trends in incidence of heart failure following acute myocardial infarction. Am J Cardiol 122:1-5

21. Cenko E, van der Schaar M, Yoon J, Manfrini O, Vasiljevic Z, Vavlukis M, Kedev S, Miličić D, Badimon L, Bugiardini R (2019) Sex-related differences in heart failure after st-segment elevation myocardial infarction. J Am Coll Cardiol 74:2379-2389

22. van der Bijl P, Abou R, Goedemans L, Gersh BJ, Holmes DR Jr, Ajmone Marsan N, Delgado V, Bax JJ (2020) Left ventricular post-infarct remodeling: implications for systolic function 
improvement and outcomes in the modern era. JACC Heart Fail 8:131-140

23. Cavender MA, Steg PG, Smith SC Jr, Eagle K, Ohman EM, Goto S, Kuder J, Im K, Wilson PW, Bhatt DL (2015) Impact of diabetes mellitus on hospitalization for heart failure, cardiovascular events, and death: outcomes at 4 years from the Reduction of Atherothrombosis for Continued Health (REACH) Registry. Circulation 132:923-931

24. Kannel WB, Hjortland M, Castelli WP (1974) Role of diabetes in congestive heart failure: the Framingham study. Am J Cardiol 34:29-34

25. Maack C, Lehrke M, Backs J, Heinzel FR, Hulot JS, Marx N, Paulus WJ, Rossignol P, Taegtmeyer H, Bauersachs J, Bayes-Genis A, Brutsaert D, Bugger H, Clarke K, Cosentino F, De Keulenaer G, Dei Cas A, Gonzalez A, Huelsmann M, Iaccarino G, Lunde IG, Lyon AR, Pollesello P, Rena G, Riksen NP, Rosano G, Staels B, van Laake LW, Wanner C, Farmakis D, Filippatos G, Ruschitzka F, Seferovic P, de Boer RA, Heymans S (2018) Heart failure and diabetes: metabolic alterations and therapeutic interventions: a state-of-the-art review from the Translational Research Committee of the Heart Failure Association-European Society of Cardiology. Eur Heart J 39:4243-4254

26. Aune D, Schlesinger S, Neuenschwander M, Feng T, Janszky I, Norat T, Riboli E (2018) Diabetes mellitus, blood glucose and the risk of heart failure: A systematic review and meta-analysis of prospective studies. Nutr Metab Cardiovasc Dis 28:1081-1091

27. Nichols GA, Gullion CM, Koro CE, Ephross SA, Brown JB (2004) The incidence of congestive heart failure in type 2 diabetes: an update. Diabetes Care 27:1879-1884

28. Dunlay SM, Givertz MM, Aguilar D, Allen LA, Chan M, Desai AS, Deswal A, Dickson VV, Kosiborod MN, Lekavich CL, McCoy RG, Mentz RJ, Pina IL (2019) Type 2 Diabetes Mellitus and Heart Failure: A Scientific Statement From the American Heart Association and the Heart Failure Society of America: This statement does not represent an update of the 2017 ACC/AHA/ HFSA heart failure guideline update. Circulation 140:e294-e324

29. Nagueh SF, Smiseth OA, Appleton CP, Byrd BF 3rd, Dokainish H, Edvardsen T, Flachskampf FA, Gillebert TC, Klein AL, Lancellotti P, Marino P, Oh JK, Alexandru Popescu B, Waggoner AD (2016) Recommendations for the evaluation of left ventricular diastolic function by echocardiography: an update from the american society of echocardiography and the european association of cardiovascular imaging. Eur Heart J Cardiovasc Imaging 17:1321-1360

30. Lombardo A, Niccoli G, Natale L, Bernardini A, Cosentino N, Bonomo L, Crea F (2012) Impact of microvascular obstruction and infarct size on left ventricular remodeling in reperfused myocardial infarction: a contrast-enhanced cardiac magnetic resonance imaging study. Int J Cardiovasc Imaging 28:835-842
31. Holmes DR Jr, White HD, Pieper KS, Ellis SG, Califf RM, Topol EJ (1999) Effect of age on outcome with primary angioplasty versus thrombolysis. J Am Coll Cardiol 33:412-419

32. Bolognese L, Neskovic AN, Parodi G, Cerisano G, Buonamici P, Santoro GM, Antoniucci D (2002) Left ventricular remodeling after primary coronary angioplasty: patterns of left ventricular dilation and long-term prognostic implications. Circulation 106:2351-2357

33. Main ML, Hannen MN, Kusnetzky LL, Martin JL, Coggins TR, Lanza P, Morris BA, Magalski A, Jones PG (2006) Myocardial contrast echocardiographic estimates of infarct size predict likelihood of left ventricular remodeling after acute anterior wall myocardial infarction. J Am Soc Echocardiogr 19:64-70

34. Florian A, Slavich M, Masci PG, Janssens S, Bogaert J (2012) Electrocardiographic Q-wave "remodeling" in reperfused STsegment elevation myocardial infarction: validation study with CMR. JACC Cardiovasc Imaging 5:1003-1013

35. Solomon SD, St John Sutton M, Lamas GA, Plappert T, Rouleau JL, Skali H, Moye L, Braunwald E, Pfeffer MA (2002) Ventricular remodeling does not accompany the development of heart failure in diabetic patients after myocardial infarction. Circulation 106:1251-1255

36. Lamblin N, Fertin M, de Groote P, Bauters C (2012) Cardiac remodeling and heart failure after a first anterior myocardial infarction in patients with diabetes mellitus. J Cardiovasc Med (Hagerstown) 13:353-359

37. Jarnert C, Melcher A, Caidahl K, Persson H, Rydén L, Eriksson MJ (2008) Left atrial velocity vector imaging for the detection and quantification of left ventricular diastolic function in type 2 diabetes. Eur J Heart Fail 10:1080-1087

38. von Lueder TG, Wang BH, Kompa AR, Huang L, Webb R, Jordaan P, Atar D, Krum H (2015) Angiotensin receptor neprilysin inhibitor LCZ696 attenuates cardiac remodeling and dysfunction after myocardial infarction by reducing cardiac fibrosis and hypertrophy. Circ Heart Fail 8:71-78

39. Wang Y, Zhou R, Lu C, Chen Q, Xu T, Li D (2019) Effects of the Angiotensin-Receptor Neprilysin Inhibitor on Cardiac Reverse Remodeling: Meta-Analysis. J Am Heart Assoc 8:e012272

40. Zhang DP, Xu L, Wang LF, Wang HJ, Jiang F (2020) Effects of antidiabetic drugs on left ventricular function/dysfunction: a systematic review and network meta-analysis. Cardiovasc Diabetol 19:10

Publisher's Note Springer Nature remains neutral with regard to jurisdictional claims in published maps and institutional affiliations. 